University of St. Thomas, Minnesota

UST Research Online

$12-2014$

\title{
A river runs between them: An instructional case in professional services provided by a CPA firm
}

Larry Davis

University of St. Thomas, Minnesota, Irdavis@stthomas.edu

Diane Matson

University of St. Thomas, Minnesota, dmmatson@stthomas.edu

Follow this and additional works at: https://ir.stthomas.edu/ocbacctpub

Part of the Accounting Commons

This Article is brought to you for free and open access by the Accounting at UST Research Online. It has been accepted for inclusion in Accounting Faculty Publications by an authorized administrator of UST Research Online. For more information, please contact asle4660@stthomas.edu. 


\title{
Educational Case
}

\section{A river runs between them: An instructional case in professional services provided by a CPA firm}

\author{
Larry R. Davis *, Diane M. Matson \\ Department of Accounting, Opus College of Business, University of St. Thomas (Minnesota), 2115 Summit \\ Avenue, St. Paul, MN 55105, USA
}

\section{A R T I C L E I N F O}

\section{Article history:}

Available online 22 October 2014

\section{Keywords:}

Attestation

Attestation standards

Attestation risk

Business risk

\begin{abstract}
A B S T R A C T
This instructional case presents a realistic situation in which there is a request for professional services by a CPA firm. Two towns, Weston and Easton, are involved in a dispute over the costs of a shared wastewater treatment facility. The mayor of Easton believes his town has paid more than its agreed-upon share of the facility's operating costs over the years. The mayor of Easton has approached a local CPA firm to "audit" the amount Easton has paid towards operation of the plant and determine the amount of the overpayment. Students are asked (1) to determine whether an audit can be performed, (2) if an audit cannot be performed, to decide what type of service is appropriate, (3) to research the applicable professional standards, (4) to assess whether the applicable standards can be met, (5) to develop a program that outlines the steps/ procedures to be completed when providing the professional service to the mayor, and (6) to identify other concerns relevant to accepting this engagement.
\end{abstract}

(c) 2014 Elsevier Ltd. All rights reserved.

\section{The Clean Water Act of $\mathbf{1 9 7 2}$}

On June 22, 1969, the Cuyahoga River in Cleveland, Ohio, caught fire when flammable liquids on its surface ignited. Those liquids were dumped into the river by industry along its banks. Ten months later, on April 22, 1970, the first Earth Day was observed. Many mark the first Earth Day as the start of the modern environmental movement in the United States. The increased public concern about the

\footnotetext{
* Corresponding author. Tel.: +(651) 9625096.

E-mail address: 1rdavis@stthomas.edu
} 
environment in the 1970s encouraged the U.S. Congress to pass and the President to sign laws designed to protect the environment. One of these laws was the Clean Water Act of 1972 (CWA).

The CWA consists of two major components. The first component regulates the pollution of surface water (such as lakes and streams) from wastewater discharged from industry and municipalities. These regulatory provisions included the requirement that industries install Best Practical Technologies (BPT) for the treatment of wastewater discharges by 1977. The second major component provides federal aid to municipalities to construct new wastewater treatment plants which will meet the Act's requirements (Copeland, 2010, p. 1).

\section{The two towns}

\subsection{History}

Easton, Minnesota, was established by North Shore Mining in 1875 as a company town for the workers employed in its iron mines in the area. All land, buildings, businesses and infrastructure (including streets and utilities) in Easton were developed, owned and maintained by North Shore. Two years later, the rival Metal Ore Mining Company established a similar company town, Weston, directly west across the St. John River from Easton.

Both Easton and Weston continued as company towns until shortly after World War II. In 1947, the two mining companies sold the houses and businesses in the two towns to their occupants. Ownership of the streets and other infrastructure, including the sewer systems, was transferred to the respective city governments.

\subsection{Impact of Clean Water Act}

Passage of the CWA presented both Easton and Weston with a major challenge. The towns were not in compliance with the new regulations. The water from the sewer systems of both towns emptied directly and untreated into the St. John River approximately one mile downstream. Also, the sanitary and storm (for rainwater) sewer systems for each town ran through the same set of sewer lines. To comply with the CWA the two towns were required to construct wastewater treatment capacity sufficient to handle both normal sanitary sewage discharge and storm water runoff from a "hundred year rain." (A "hundred year rain," the largest amount of rainfall that could fall in one day in any one year with a probability of $1 \%$ or greater, is often used to establish the minimum size requirement for a municipal storm sewer system). Clearly, the towns would need to upgrade their wastewater treatment to meet the new law's provisions.

\subsection{Construction and operation of treatment plant}

In 1973, both towns commissioned engineering studies to evaluate the feasibility and costs of building and operating new wastewater treatment plants. Those studies indicated that the least costly alternative for both towns would be a shared treatment plant located on the Easton side of the river. Wastewater from Easton could be sent to the treatment plant via that town's existing discharge sewer line. Water from Weston could be sent to the plant via a new sewer line running under the river from Weston and connected to the existing Easton discharge sewer line between Easton and the treatment plant. See Fig. 1.

In 1975, the St. John River Water Authority (SJWA), a new governmental agency, was created to obtain a federal grant under the CWA, construct the plant and operate it. The grant was quickly obtained, and the new treatment plant and sewer lines from Weston were constructed in 1975. In early 1976 the plant began treating the two towns' wastewater.

The two towns agreed to cover the operating costs of the treatment plant in proportion to the amounts of water each sent to the plant. To measure the amounts of water, two meters were installed. The first meter was installed on the sewer line running from Weston to Easton where the sewer line entered the river on the Weston side of the river. This meter was used to measure the water Weston sent to the plant. The second meter was installed on the sewer line carrying both Easton's and Weston's water 


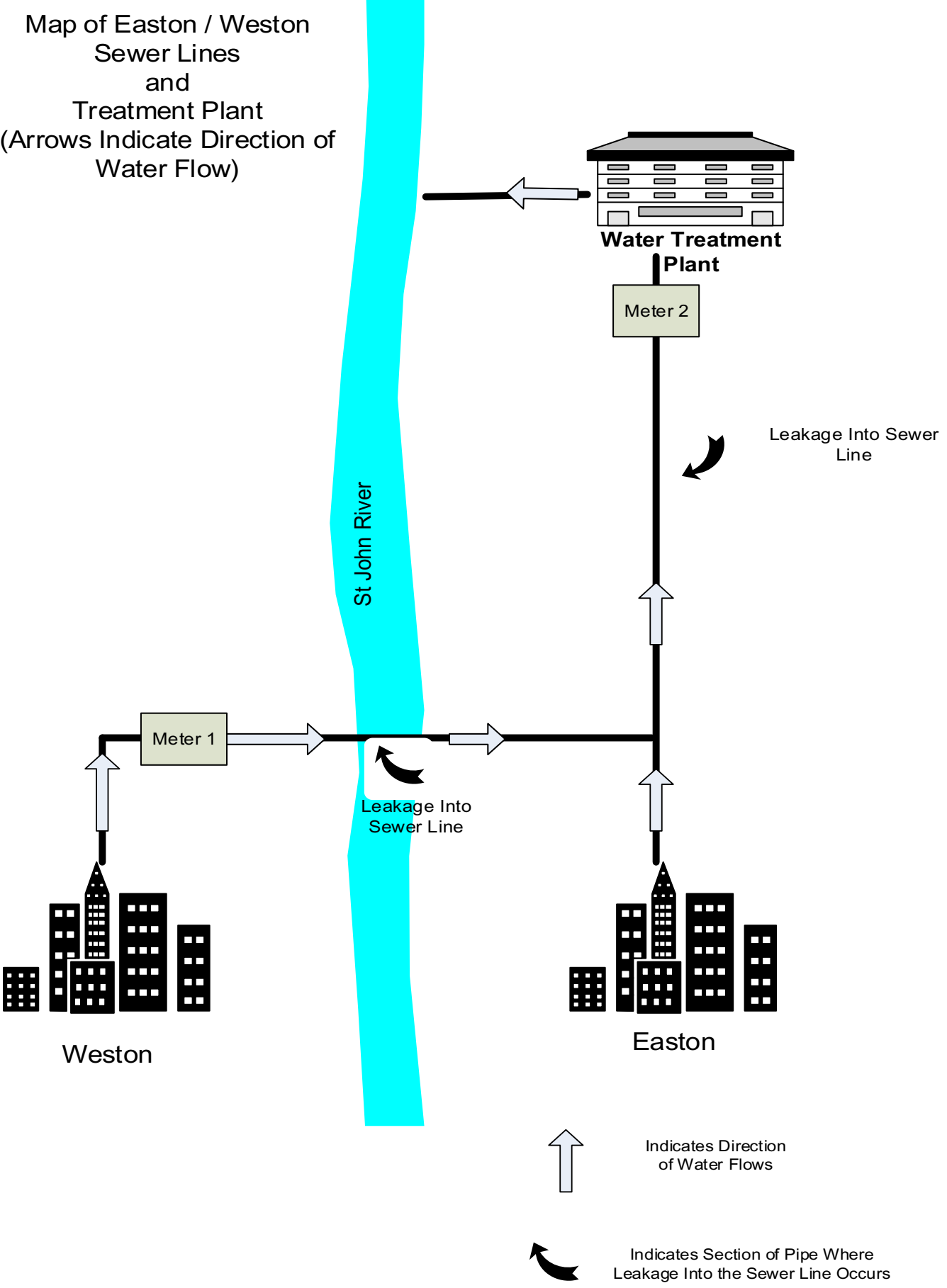

Fig. 1. Easton/Weston Sewer Lines. 
where it entered the treatment plant and measured the total volume of water entering the plant. Easton's water was then calculated as the difference between the total water entering the plant per the second meter and the amount attributed to Weston per the first meter. The basic equation was: Easton's Water = Total Water - Weston's Water.

The SJWA was responsible for tracking the costs of operating the treatment plant, measuring the amounts of water entering the facility attributable to each town as described above, and preparing the annual cost allocations. Under its charter, the SJWA provided a set of audited financial statements, including a footnote containing a schedule of operating costs, to the two towns each year. The water flow measurements and cost allocations were provided in a separate report and were not audited. Further, the two towns retained the right to review SJWA's accounting records and observe the water meters.

A schedule of operating costs and proportions charged to each town for the 5 most recent years is provided in Exhibit 1.

\subsection{Financial difficulties}

The first 15 years of the twenty-first century were difficult financially for Easton and Weston. Declining profitability of Minnesota ore mines resulted in lower corporate profits, lower tax revenues, and higher unemployment for both towns. In addition, the federal government reduced its payments to state and local governments as a result of increasing national deficits.

In November 2015, the new mayor of Easton requested a study to investigate ways in which Easton could save money. One of the study's findings was that Easton had been paying approximately twice as much of the operating costs of the wastewater treatment plant as had Weston. This was a surprising discovery because the two cities were approximately equal in population (6,000 residents each) with comparable levels of commercial activity.

Further investigation by Easton's Public Works Department revealed significant leakage into the sewer pipe running under the river from Weston to Easton. There was also significant leakage into the pipe entering the treatment plant after the two pipes from Weston and Easton merged. Consequently, the total water entering the plant included the water sent by Weston, the water sent by Easton plus the water leaking into the pipes after they exited the two towns. Because the amount of water sent to the treatment that was attributed to Weston was based on the meter close to where the sewer pipes left that town, it did not include, much, if any, of the water leaking into the pipe where it ran under the river or where it ran between the junction of the two towns' pipes and the treatment plant. Because all water not attributed to Weston was attributed to Easton, the water attributed to Easton included the water discharged from that town and the leakage into the pipe where it ran under the river and where it ran between the junction of the two towns' pipes and the treatment plant. Thus, Easton appeared to be sending more water to the treatment plant than it really did. Some of this water should have been attributed to Weston. Easton was paying more than its agreed-upon share.

\section{The mayor's request}

Immediately after learning of the leakage and its consequences in January of 2016, the mayor of Easton called a press conference and vowed to recover, from Weston, the amount Easton had "overcontributed" to the operating costs of the wastewater treatment plant over the last 40 years. The mayor's first action after the press conference was to meet with Easton's local CPA firm, Backman and Lodder, CPAs, LLP. The mayor asked the firm to conduct an audit of the costs of operating the wastewater treatment plant and the allocation of these costs for the previous 40 years.

\section{Case questions}

For each of the Questions, below, please explain your answers and provide citations to the relevant professional standards and other sources. 
Exhibit 1

Easton and Weston Water Treatment Plant Allocation of Gallons and Costs.

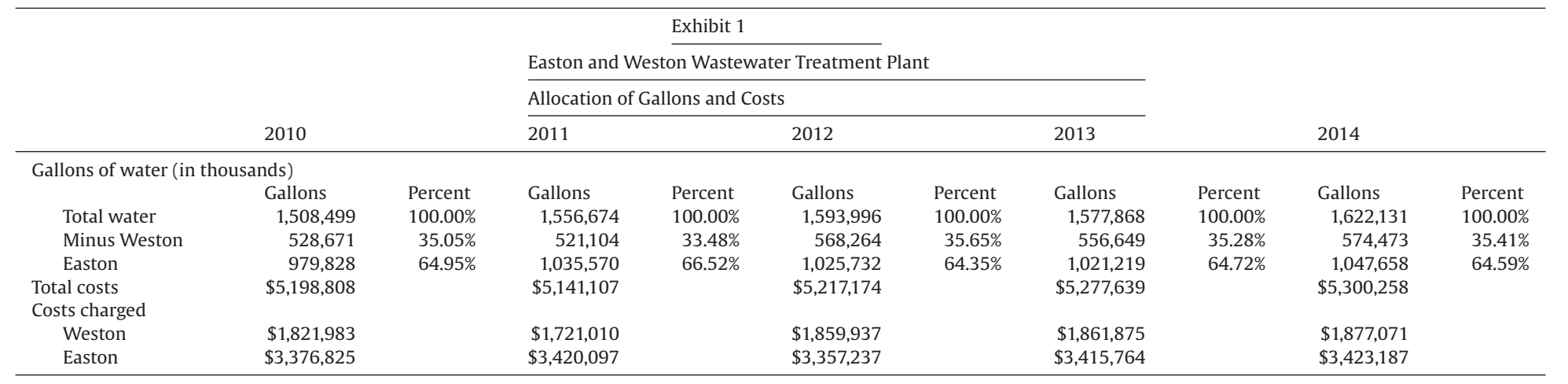


1. a. Does the service requested by Easton's mayor constitute an audit of financial statements?

b. Consider the possibility that the service does not qualify as an audit. Are there other types of services that the accountant could provide to address the mayor's concerns? If so, what are these services? Which professional standards would be relevant to the other types of services?

c. Which type of service do you believe a practitioner would prefer? Which type do you believe the mayor of Easton would prefer?

2. Assume the firm is going to provide an attestation service. How are the attestation standards different from and similar to Principles Underlying an Audit in Accordance with Generally Accepted Auditing Standards? Who would be the engaging party and the responsible party?

3. Assume the mayor proposes the following:

- A new, third meter will be installed where the sewer line exits Easton.

- The amounts of wastewater sent to the treatment plant from the two cities over the next year would then be measured based on readings of the meters where the sewer lines exit the two cities.

- Prior years' costs for the plant would be reallocated based on the relative amounts of wastewater sent to the treatment plant over the next year.

- The mayor would then provide a written assertion that the revised allocations fairly present what prior year's allocations would have been if based on the actual amounts of wastewater sent to the treatment plant by the two towns.

a. Could Backman and Lodder perform an examination and issue an opinion on the mayor's assertion in accordance with the attestation standards? In particular, address whether the preconditions, performance standards and reporting standards could be met.

b. If any of the preconditions or standards could not be met, is there a way in which the engagement could be modified so that they could be met?

4. Prepare each program as indicated below.

a. Prepare a program (e.g., a list of procedures to perform) for an Examination Engagement for the service described in Question 3.

b. Prepare a program for a Review Engagement for the service described in Question 3. The town would supply census data and real estate value assessment data.

c. Prepare a program for an Agreed-upon Procedures engagement to meet the mayor's request for service assuming the new meter where the sewer line exits Easton is installed as described in Question 3. The mayor specifies the following procedures to be performed by the practitioner using data to be supplied by Easton:

- Observe the water meter readings on the sewer lines where they exit Easton and Weston at the beginning and end of the measurement period.

- Perform the cost reallocations based on the meter readings at the beginning and end of the measurement period and prior years' costs schedules from SJWA annual reports.

- Use decennial U.S. census data from 1970 through 2010 to prepare a report showing all instances in which one town's population was more than $110 \%$ of the other town's.

- Prepare, for every tenth year beginning in 1970, a report based on the two towns' assessed property values - both in the aggregate and by zoning classification - identifying all years in which one town's assessed property value was more than $110 \%$ of the other town's.

All data would be supplied by the town of Easton.

5. What other factors beyond the ability to comply with Professional Standards should be considered when deciding whether to accept this engagement?

\section{Teaching notes}

These teaching notes discuss objectives and implementation and address learning efficacy. The suggested solutions are available from the corresponding author. 


\subsection{Objectives}

We have used this case in both the first (introductory) auditing course, at the undergraduate or graduate level, and in the second (advanced) auditing course, also at the undergraduate or graduate level. In introductory auditing, we use the case to illustrate the differences between financial statement audits and attestation engagements, and between Auditing Standards and Attestation Standards. In advanced auditing, we use the case to emphasize how attestation standards are applied, and what issues and concerns may arise in non-traditional attestation services. In both classes we use the case to illustrate the numerous issues and risks that must be considered when accepting an engagement.

After completing this case, students should be able to:

1. Describe the different types of attestation services.

2. Identify and assess whether the conditions necessary for the performance of an attestation engagement have been met.

3. Identify the wide variety of issues practitioners consider in deciding whether to accept an engagement.

4. Identify procedures that can be performed to comply with the attestation standards.

5. Prepare a program for an attestation engagement.

6. Identify practitioner business risks associated with attestation engagements.

\subsection{Implementation}

We discuss the case after the students have been asked to read the text material covering the Auditing Standards and the Attestation Standards. The case is typically handed out or made available electronically one class period prior to the one in which it is discussed. In the introductory auditing course, undergraduates are asked to prepare a two to three page outline (e.g., bullet points) of their case answer, focusing primarily on the first three questions. Graduate students are generally asked to prepare a five to seven page written case solution memo for all five questions. In both instances, the students' answers are collected and counted as a homework assignment.

In class, we begin by asking the students to identify the appropriate classification of the service the mayor is requesting. Students generally reach a consensus fairly quickly, suggesting that the service would be a non-audit attestation engagement. Once they have decided that the engagement would not be an audit, they soon identify the Attestation Standards as the appropriate professional stan-

Table 1

Student opinion survey results.

\begin{tabular}{ll}
\hline Survey statement & Mean (Std. Dev.) \\
\hline 1. This case is interesting. & $1.32^{* *}(0.81)$ \\
2. The case questions were clear. & $1.78^{* *}(2.02)$ \\
3. The case helped me understand differences between financial & $1.76^{* *}(1.3)$ \\
$\quad$ statement audits and other attestation services. & $1.89^{* *}(1.22)$ \\
$\begin{array}{l}\text { 4. The case helped me to understand the Attestation Standards. } \\
\text { 5. The case helped me understand how the Attestation Standards } \\
\quad \text { are met in practice. }\end{array}$ & $1.96^{* *}(2.25)$ \\
6. The case helped me understand how factors other than just the \\
$\begin{array}{l}\text { ability to comply with professional standards may affect accountants } \\
\text { decision to accept an engagement. }\end{array}$ \\
$\begin{array}{l}\text { 7. The case helped me understand the risks associated with providing } \\
\text { attestation services. }\end{array}$ \\
8. I learned a lot from this case. & $2.05^{*}(1.2)$ \\
\hline
\end{tabular}

Scoring: 1 = Strongly Agree; 2 = Agree; 3 = Neither Agree nor Disagree; 4 = Disagree; $5=$ Strongly Disagree.

$n=94$.

* Significantly different from midpoint (3, Neither Agree nor Disagree) at $<0.05$.

** Significantly different from midpoint (3, Neither Agree nor Disagree) at $<0.01$. 
Table 2

Learning assessment quiz questions.

Question

Percentage correct answers

Pre-test Post-test

$85 \% \quad 94 \% *$

1. An audit involves an examination of which of the following?

a. An assertion

b. Financial information

c. Financial statements

d. Financial forecasts

2. Which of the following is a practitioner not required to do when performing attestation services other than an audit?

a. Maintain independence

b. Exercise due professional care

c. Obtain an understanding of the entity and its environment, including its internal control

d. Issue a report

3. When performing an attest engagement, the practitioner evaluates the subject matter against:

a. Generally Accepted Accounting Standards

b. Generally Accepted Auditing Standards

c. Criteria that are selected by the client and that are suitable and

available to users

d. Criteria that are developed by the practitioner that are suitable and available to users

4. An attestation engagement that qualifies as a review of the subject matter is intended to provide:

a. No assurance

b. A low level of assurance

c. A moderate level of assurance

d. A high level of assurance

5. A CPA is engaged to provide assurance about an assertion by Smith Corporation's

management that their corporate website has met standards set by the Online Transaction Standards Committee for secure transaction processing. The Responsible Party in this would be:

a. Smith Corporation's management

b. Smith Corporation

c. the CPA performing the engagement

d. the Online Transaction Standards Committee

6. Which of the following would meet the definition in the attestation standards of an examination? $50 \%$
a. Preparation of a client's annual tax returns
b. An audit of financial statements
c. A review of financial statements
d. A compilation of financial statements

7. For which of the following types of services would the report provide positive assurance?
a. An examination
b. A review
c. A compilation
d. An Agreed-upon procedures engagement

8. When performing an attestation engagement considered to be a review, the practitioner would normally collect:

a. evidence from sources independent of the client

b. evidence consisting primarily of client inquiry and analytical review

c. evidence consisting of verification of the arithmetical accuracy of the client's records

d. evidence sufficient to reduce attestation risk to a low level

Answers: 1. C. 2. C. 3. C. 4. C. 5. A. 6. B. 7. A. 8. B. $n=94$

* Difference in percentage correct answers significant at $<0.05^{* *}$ Difference in percentage correct answers significant at $<0.01$. 
dards to guide the work. We try to emphasize the similarities and differences between the Auditing Standards and the Attestation Standards. Both sets of standards require, for example, proficiency and independence. The standards differ significantly, however, on the underlying criteria and on reporting. In the advanced auditing course, students are also required to address all the questions, spending additional time on the preparation of programs for the different types of engagements (Question 4) and addressing other factors to consider in deciding whether to accept the engagement (Question 5).

A critical question in this case is whether current water flows can be used as a reasonable basis for reallocating prior years' costs. The criteria would be accurate measures of the water sent to the plant in prior years by each town - information that is not available since time has passed. Other important questions involve the appearance of independence, significant reservations about the engagement, and possible restriction of the intended users of the report. We also try to encourage discussion about various risks related to this type of engagement, such as legal liability and loss of reputation, and challenge the students to generalize their concerns to other new or nontraditional forms of attestation services.

\subsection{Evidence of efficacy}

The results of a student survey administered after discussions of the case are shown in Table 1. Responses from 68 undergraduate auditing students and 26 graduate advanced auditing students are included. There were no qualitative differences between the two groups of students and so the results are pooled. In general, the students found the case interesting and the case expectations clear. They perceived that the learning objectives are being met. Anecdotal responses from students after class and on semester-end teaching evaluations are consistent with the results shown in Table 1.

In addition to the student survey, we also asked the students to take a multiple choice question quiz immediately before and after discussing the case. The attestation standards section of the course text was part of the students' assigned reading to be done before the day on which the quiz was administered and the case discussed. The quiz questions and results of two administrations of the quiz are shown in Table 2. These results are consistent with those in Table 1 and further indicate a positive effect from covering the case.

\subsection{Alternative use}

We have used this case, and present it here, as a vehicle to introduce students to the attestation standards. We wish to thank one of the reviewers for pointing out that it could also be used as an example of a management accounting case or a consulting engagement case. As an attestation engagement, the practitioner's role is primarily to add credibility to revised cost allocations. As a management accounting or consulting engagement, the accountant would be more likely to be involved in resolving the dispute. For example, the accountant might become involved by working with engineers to determine the amount and nature of leakage into the pipes, the reliability and accuracy of the meters, or the design of a new measurement system (e.g., relocation and installation of existing or new meters). Similarly, the case could be used in capstone course in which the differing roles of accountants (e.g., assurance agent, consultant or management accountant) are discussed.

\section{Reference}

Copeland, C. (2010). Clean water act: a summary of the law. Washington, DC: Congressional Research Service. 